\title{
The Effect of Microsilica and Aluminum Metal Powder on the Densification Parameters, Mechanical Properties and Microstructure of Alumina-Mullite Ceramic Composites
}

\author{
M. M. S. Wahsh ${ }^{1}$, H. E. H. Sadek ${ }^{1}$, S. Abd El-Aleem ${ }^{2}$, * H. H. M. Darweesh ${ }^{1}$ \\ ${ }^{1}$ Refractories, Ceramics and Building Materials Department, National Research Centre, Cairo, Egypt \\ ${ }^{2}$ Chemistry Department, Faculty of Science, Fayoum University, El-Fayoum, Egypt
}

Email address:

saa09@fayoum.edu.eg (S. Abd El-Aleem),mmswahsh@yahoo.com (M. M. S. Wahsh)

\section{To cite this article:}

M. M. S. Wahsh, H. E. H. Sadek, S. Abd El-Aleem, H. H. M. Darweesh. The Effect of Microsilica and Aluminum Metal Powder on the Densification Parameters, Mechanical Properties and Microstructure of Alumina-Mullite Ceramic Composites. Advances in Materials. Vol. 4, No. 4, 2015, pp. 80-84. doi: 10.11648/j.am.20150404.12

\begin{abstract}
Microsilica, or silica fume, is an amorphous type of silica mostly collected as byproduct of the silicon and ferrosilicon alloy production. In this work, low shrinkage alumina-mullite ceramic composites were prepared from mixtures of calcined alumina, silica fume and aluminum metal powder and sintered at $1550^{\circ} \mathrm{C}$ for $2 \mathrm{hrs}$. The influence of silica fume and aluminum powder on the densification parameter, in situ mullite formed and mechanical properties of sintered samples were studied. The phase composition and the microstructural evolution of the sintered samples were also investigated. The results showed that, silica fume enhances the mechanical properties of sintered samples, while the aluminum powder improves the mullite formation process. Ultra low shrinkage (close to zero), and good mechanical properties (CCS $\approx 70 \mathrm{MPa}$ ) of aluminamullite ceramic composites were achieved. Alumina-mullite ceramic composites are considered a promising material for high temperature applications.
\end{abstract}

Keywords: Ceramics, X-ray Diffraction, Mechanical Properties, Microstructure

\section{Introduction}

Silica fume (SF) is a by-product of the smelting process in the silicon and ferrosilicon industry. Because of its extreme fineness, high compressive strength, high tensile, high flexural strength, high modulus of elasticity, higher bond strength, very low permeability to chloride and water intrusion, increased abrasion resistance on decks, floors, overlays and marine structures, superior resistance to chemical attack from chlorides, acids, nitrates and sulfates and life-cycle cost efficiencies, silica fume is a promising material to use in ceramics application as a source of silica. Also, the high surface area and amorphous nature of silica fume make it highly reactive [1].

Alumina ceramics are relatively low cost, high melting point, excellent mechanical properties such as: high hardness, high compressive strength, good chemical, thermal stability and a high elastic modulus. Also, the alumina ceramic components have been manufactured with a high output using different methods, e.g. by pressing; slip casting; injection moulding; etc., without the use of expensive equipment such as kilns with special controlled atmosphere [2-4]. One of the commonly used approaches to modify alumina ceramics in order to attain desirable properties is the creation of a secondary crystalline phase. Mullite (3Al2O3.2SiO2) is a characteristic constituent of all ceramic products made from aluminosilicates, and has become a candidate for a high-temperature structural ceramic [5-9], because of its excellent physical properties, such as low dielectric constant, low thermal expansion, high melting point, high resistance to creep and chemical corrosion, high temperature mechanical stability, and thus high thermal shock resistance [10-14]. Therefore, mullite is considered a suitable secondary crystalline phase and corundum-mullite composites are made according to appropriate ratio of alumina and mullite [15]. Alumina - mullite composite has better overall properties than pure corundum or pure mullite and has been considered one of the most promising high temperature structural ceramics for gas turbine engines, burner tubes and heat shields for re-entry space vehicles $[12$, 16].

Only several years ago, the reaction bonding of aluminum 
oxide (RBAO) was developed by Claussen and his colleagues [17-19] as a novel technique to fabricate high strength, fine grained and low shrinkage alumina ceramics. In this technique, $\mathrm{Al}+\mathrm{Al} 2 \mathrm{O} 3$ powder compacts are heat-treated in air to melt and oxidize the Al metal into nano-sized Al2O3 crystallites, which bond with the originally added Al2O3 particles and co-sinter to high density. Extensively, the RBAO technique has been successfully applied to produce low-shrinkage mullite ceramics by incorporating $\mathrm{SiC}$ into the initial $\mathrm{Al}+\mathrm{Al} 2 \mathrm{O} 3$ powder mixture [20-22]. During heattreatment, $\mathrm{SiC}$ is oxidized to $\mathrm{SiO} 2$, which reacts with the newly-formed and/or originally added $\mathrm{A} 12 \mathrm{O} 3$ to form mullite.

The aim of the present work is the preparation and characterization of alumina-mullite ceramic composites. Furthermore, the role of silica fume and aluminum powder additions on the densification behavior and mechanical properties of the prepared samples was studied.

\section{Materials and Experimental Details}

The starting materials used in this study are a commercial calcined alumina powder $(\alpha-\mathrm{A} 12 \mathrm{O} 3$, with a mean particle size $\leq 10 \mu \mathrm{m}$, Alexandria Refractories Company, Egypt), silica fume (with a surface area of $21 \mathrm{~m} 2 / \mathrm{g}$ was provided by Ferrosilicon Alloys Company, Edfo, Egypt) and aluminum metal (Aluminum powder, $<5 \mu \mathrm{m}$, Sigma-Aldrich, UK). The chemical compositions of the starting materials are given in Table (1). Aluminum metal was added to alumina-silica fume composition up to 12 mass; \% at the expanse of silica fume content with increment 4 mass; $\%$, the batch composition of the samples was illustrated in Table (2). After well mixing, the batches were uniaxially pressed at a pressure of $200 \mathrm{MPa}$, and dried at $110 \mathrm{oC}$ for $24 \mathrm{hrs}$. Then, the samples were set in an electric furnace and gradually fired at $1550 \mathrm{oC}$ for $2 \mathrm{hrs}$ as soaking time.

Table 1. Chemical composition of the starting materials, mass $\%$

\begin{tabular}{|c|c|c|c|c|c|c|c|c|c|c|c|}
\hline & $\mathbf{A l}_{2} \mathbf{O}_{3}$ & $\mathrm{SiO}_{2}$ & $\mathrm{Fe}_{2} \mathrm{O}_{3}$ & $\mathrm{CaO}$ & MgO & $\mathrm{Na}_{2} \mathrm{O}$ & $\mathrm{K}_{2} \mathrm{O}$ & $\mathrm{SO}_{3}$ & $\mathrm{PO}_{4}$ & $\mathrm{TiO}_{2}$ & L.O.I. \\
\hline Calcined alumina & 98.20 & 0.74 & 0.40 & 0.26 & 0.05 & 0.10 & 0.04 & $\begin{array}{ll}-- \\
--\end{array}$ & $\begin{array}{ll}-- \\
--\end{array}$ & 0.21 & --- \\
\hline Silica fume & 0.50 & 94 & 1.23 & 0.32 & 0.42 & 0.23 & 0.25 & 0.24 & 0.25 & --- & 2.56 \\
\hline
\end{tabular}

Table 2. Batch design of the investigated samples A0-A12, mass\%.

\begin{tabular}{cccc}
\hline Sample & Calcined alumina & Silica fume & Aluminum metal \\
\hline A0 & 84 & 16 & 0 \\
A4 & 84 & 12 & 4 \\
A8 & 84 & 8 & 8 \\
A12 & 84 & 4 & 12 \\
\hline
\end{tabular}

Densification parameters such as bulk density (BD) and apparent porosity (AP) of the sintered samples were determined by using Archimedes method according to ASTM: C20-00. Linear change was examined by measuring diameter of the samples before and after sintering. Also, cold crushing strength (CCS) was measured by using a hydraulic press machine (SEIDNR - Riedlinger type, Germany) according to ASTM: C133-97. The X-ray diffraction (XRD) data were obtained using Philips 1730 diffractometer with a Ni filtered $\mathrm{Cu}-\mathrm{K} \alpha$ radiation at a scanning speed of $1 \mathrm{o} / \mathrm{min}$. Scanning Electron Microscopy (SEM; JXA- 840A electron probe microanalyzer, JEOL) has been carried out on the fractured surface of sintered specimen to study the crystal morphology.

\section{Results and Discussion}

\subsection{XRD of the Sintered Composites}

Fig. 1 shows the XRD pattern of sintered samples A0-A12 fired at $1550 \mathrm{oC}$. The major identified crystalline phases are corundum and mullite $(3 \mathrm{Al} 2 \mathrm{O} 3 \cdot 2 \mathrm{SiO} 2)$, in all samples. Also, weak diffraction peaks of $\mathrm{SiO} 2$ ( $\beta$-Cristobalite) and aluminum metal (Al) were found in samples $\mathrm{A} 0$ and $\mathrm{A} 12$, respectively. From Fig.1, it was observed that, the peak intensity of mullite phase gradually decreased with the increasing of aluminum powder content as well as $\mathrm{SiO} 2$ disappeared in sample A4 with 4 mass \% of aluminum powder. The mullitization process started at the contact interface between alumina and silica present in the starting powders during firing. Aluminum metal supports the reaction of $\mathrm{SiO} 2$ with $\mathrm{Al} 2 \mathrm{O} 3$ to form mullite phase which is melt at a low temperature $\left(\approx 660^{\circ} \mathrm{C}\right)$ and formed active alumina by oxidation of aluminum metal during the firing process [23]. The active alumina reacted vastly with silica grains in the composition and formed mullite. This mullite becomes the nucleation site of mullite formation. In sample A4, all $\mathrm{SiO} 2$ reacted with alumina to form mullite phase. The excess of alumina present in the composition has given rise to the corundum phase. Mullite and corundum are the only crystalline phases in samples A4 and A8.

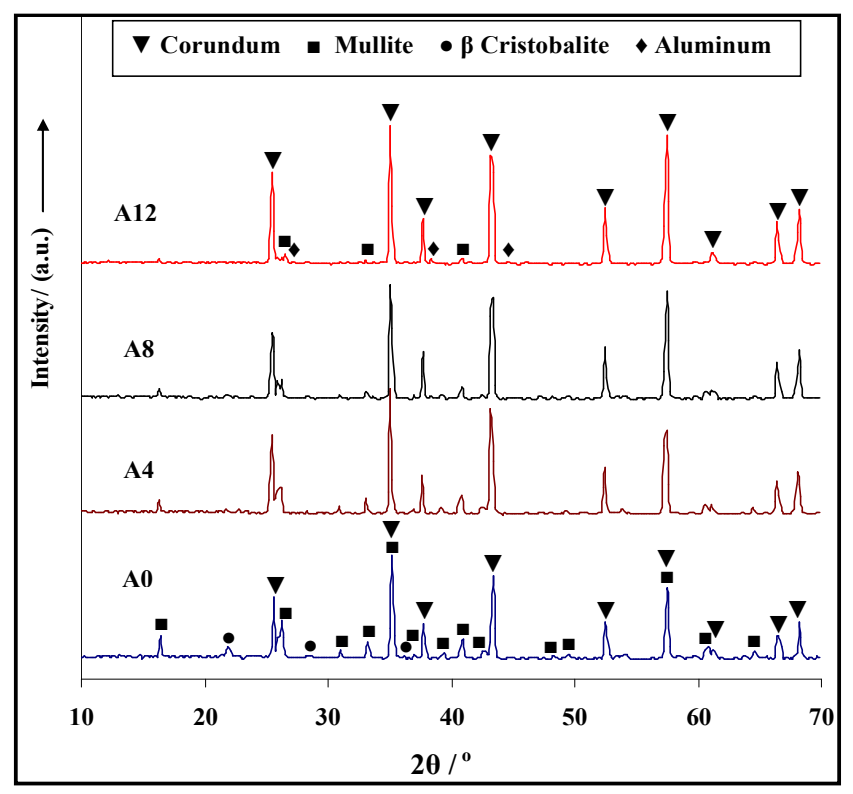

Fig. 1. XRD patterns of the samples A0-A12 sintered at $1550^{\circ} \mathrm{C}$ for $2 \mathrm{hrs}$ 


\subsection{Densification Parameters}

Fig. 2 shows the bulk density (BD) and apparent porosity (AP) of the sintered samples A0-A12. With increasing of aluminum powder from sample A0 to A12, the bulk density was decreased and the apparent porosity was increased. This is due to the amount of mullite phase decreased from sample A0 to A12 with decreasing of silica fume content. Sample A0 achieved the higher densification parameter due to the mullitization process. Mullite crystals and the viscous glassy phase occupied the pore spaces were reduced the porosity. However, samples A8 and A12 exhibited the lowest bulk density and the highest apparent porosity due to the low contents of mullite and liquid phases.

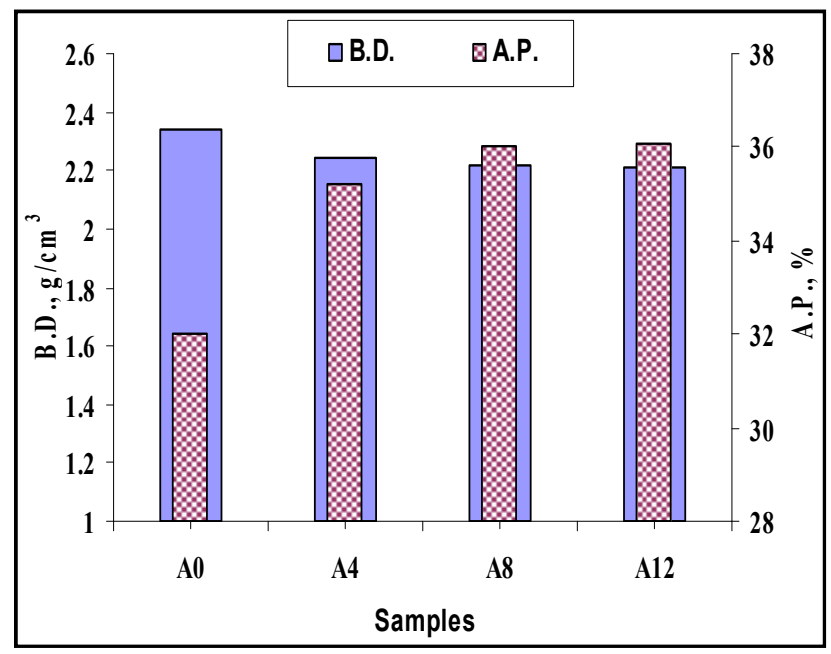

Fig. 2. Bulk density and apparent porosity of the samples A0-A12 sintered at $1550^{\circ} \mathrm{C}$ for $2 \mathrm{hrs}$

\subsection{Linear Change}

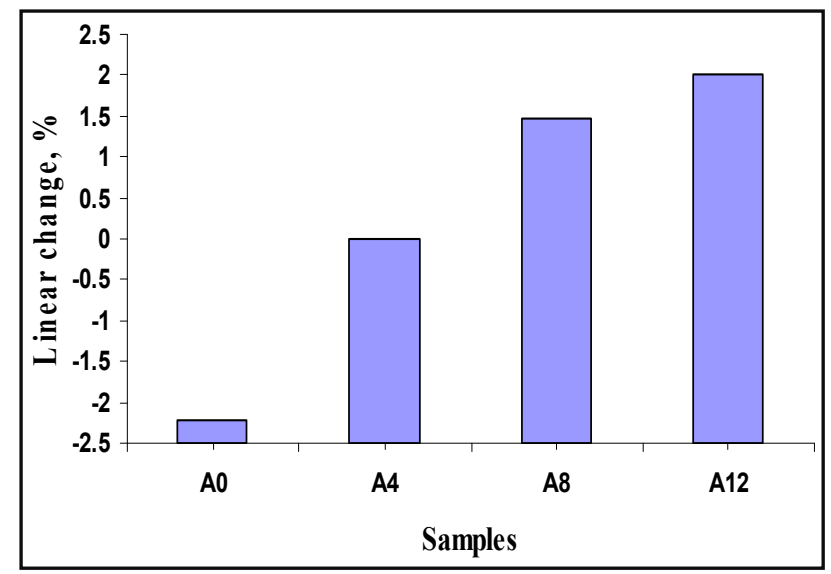

Fig. 3. Linear change of the samples A0-A12 sintered at $1550^{\circ} \mathrm{C}$ for $2 \mathrm{hrs}$.

The linear change increases with the increase of aluminum metal from sample A0 to A12 as shown in Fig. 3. The low linear change (shrinkage) of sample A0 has resulted from the crystalline structure of corundum - mullite crystals and glassy phase matrix. The formation of glassy phase enhanced the sintering of the samples. Also, the mean thermal expansion coefficients of alumina and mullite are $8.8 \times 10-6$ and
$5.3 \times 10-6 \mathrm{~K}-1$, respectively [24-26]. Since the thermal expansion coefficient of alumina is higher than that of mullite, the residual stress states in alumina/mullite composites which are such that the second phase particles, are in approximately hydrostatic compression, and there are tensile hoop stresses in the surrounding matrix. However, with decreasing of silica fume in the samples, the mullite and glassy phase matrix were decreased. Sample A4 (containing 4 mass; \% of aluminum metal) has ultra low shrinkage close to zero. Samples A8 and A12, exhibit the expansion behavior due to the reaction mechanism of active alumina formation and decreasing of mullite and glassy phases.

\subsection{Cold Crushing Strength (CCS) of the Samples A0-A12}

All samples have a good cold crushing strength $(\approx$ around $70 \mathrm{MPa}$ ), as shown in Fig. 4. This is mainly due to a good crystalline of corundum and mullite phases' formation. In addition, the matrix grain boundaries were reinforced by the formation of mullite phase. In the meantime, the counter force of particle compressive stresses (due to the difference in the thermal expansion coefficients of alumina and mullite) can be passed to the grain boundaries, thereby in strengthening it. The strengthening effect of intragranular residual stresses on grains and grain boundaries increase with the second phase content. When the strength of the grain boundaries is close to that of the grains, the transgranular fracture dominates [26, 27]. The CCS decreased from sample $\mathrm{A} 0$ to A12. This is due to two factors; the first is the increase of apparent porosity and the second is the decrease of mullite content. The two factors work together to reduce the mechanical properties of the investigated samples. Porosity has the opposite effect on the mechanical properties of the samples.

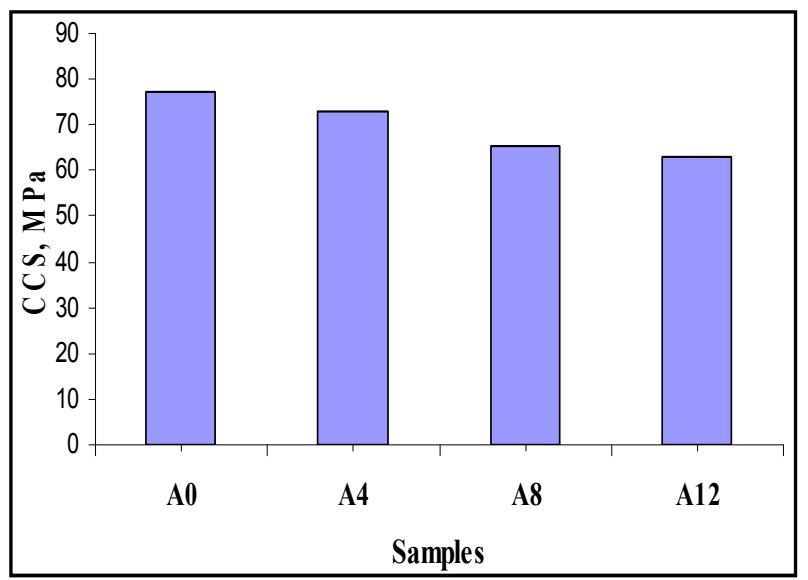

Fig. 4. Cold crushing strength of the samples $A 0-A 12$ sintered at $1550^{\circ} \mathrm{C}$ for 2 hrs.

\subsection{Microstructure}

Fig.5 shows the scanning electron microphotographs of the samples A4 and A12 sintered at $1550 \mathrm{oC}$ for $2 \mathrm{hrs}$. Generally, the spherical corundum grains are uniformly dispersed throughout the mullite matrix. The needle shaped mullite 
crystals are randomly oriented and interlocked together giving rise to a good compact microstructure [28]. In the sample A4 (with 4 mass; \% aluminum powder, 12 mass; \% silica fume and 84 mass; \% calcined alumina), the grains of corundum and mullite developed large and intertwined crystals. Most of mullite developed needle-like structure and grew together. However, sample A12 (with 12 mass; \% of aluminum powder, 4 mass; \% silica fume and 84 mass; \% calcined alumina), grain size of mullite and corundum is small and a small amount of shorter length, needle-like mullite particles can been observed. This is mainly due to that, the amount of mullite in the ceramic matrix is strongly depends on the silica content in the starting chemical compositions of the investigated samples. Clearly, aluminum powder promoted the formation of columnar mullite. This is because molten aluminum wets some mullite and $\mathrm{SiO} 2$ grains. According to the two dimensional nucleation theories [23, 29], the interface wetted by molten aluminum has a small nucleation potential barrier, large nucleation rate and fast moving rate. This supports the growth of columnar crystals on the wetting interfaces. Therefore, columnar mullite content in corundum-mullite material increased with the increasing content of aluminum powder. This is consistent with the reports in the literature that liquid phase is advantageous in forming the columnar mullite [30].
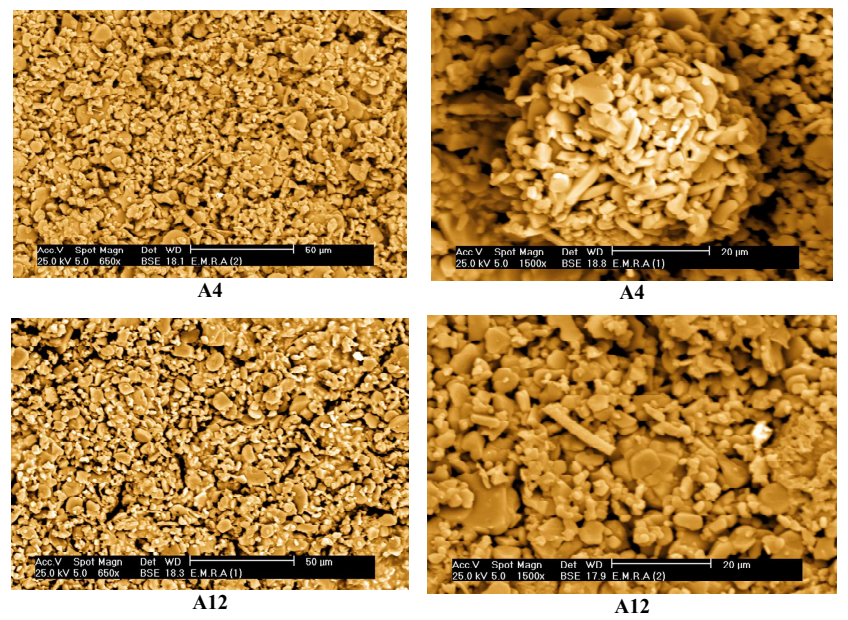

Fig. 5. SEM microphotograph of the samples $A 4$ and $A 12$ sintered at $1550^{\circ} \mathrm{C}$ for 2 hrs

\section{Conclusions}

- Mullite phase was formed due to the solid state reaction mechanism of alumina and silica at a sintering temperature of $1550^{\circ} \mathrm{C} ; 3 \mathrm{Al}_{2} \mathrm{O}_{3}+2 \mathrm{SiO}_{2} \rightarrow 3 \mathrm{Al}_{2} \mathrm{O}_{3} \cdot 2 \mathrm{SiO}_{2}$

- Silica fume improved the mechanical properties of the sintered samples due to mullite phase formation process.

- Aluminum metal enhances the reaction of $\mathrm{Al}_{2} \mathrm{O}_{3}$ with $\mathrm{SiO}_{2}$ to form mullite phase through the formation of active alumina.

- Mullite crystals and the viscous glassy phase play an important role to improve the densification parameters and mechanical properties of the samples.
- Microstructure indicated that aluminum powder promoted the formation of columnar mullite in the matrix of the samples in a good contact with corundum and primary mullite.

Sample A4 (containing 84 mass; \% calcined alumina, 12 mass $\%$ fume silica and 4 mass $\%$ aluminum metal powder) can be selected for preparation of alumina - mullite ceramic composites with ultra low shrinkage (close to zero) and good mechanical properties $(\mathrm{CCS} \approx 70 \mathrm{MPa})$.

\section{References}

[1] Siddique R., Khan M.I., Supplementary cementing materials, chapter 2, silica fume, Springer-Verlag Berlin Heidelberg, (2011).

[2] Wahsh M.M.S., Khattab R.M., Awaad M., Thermo-mechanical properties of mullite/zirconia reinforced alumina ceramic composites, Mater. Design, 41 (2012) 31-36.

[3] Bakr I.M., Wahsh M.M.S., Fabrication and characterization of multi phase ceramic composites based on zircon-aluminamagnesia mixtures, Mater. Design, 35 (2012) 99-105.

[4] Medvedovski E., Alumina-mullite ceramics for structural applications, Ceram. Int., 32 (2006) 369-375.

[5] Aksel C., The effect of mullite on the mechanical properties and thermal shock behaviour of alumina-mullite refractory materials, Ceram. Int., 29 (2003) 183-188.

[6] Takei T., Kameshima Y., Yasumori A., Okada K., Crystallisation kinetics of mullite in alumina-silica glass fibers, J. Am. Ceram. Soc., 82 (1999) 2876-2880.

[7] Ghate B.B., Hasselman D.P.H., Spriggs R.M., Synthesis and characterization of high purity, fine grained mullite, Am. Ceram. Soc. Bull., 52 (1973) 670-672.

[8] Ibrahim D.M., Naga S.M., Kader Z.A., Salam E.A., Cordierite- mullite refractories, Ceram. Int., 21 (1995) 265269.

[9] Zhong X.C., Sun G.C., Thermomechanical properties of corundum-mullite-zirconia materials, in: UNITECR '97, Proc. Unified Int. Tech. Conf. on Refractories, $5^{\text {th }}$ Biennial Worldwide Congress, Refractories-A Worldwide Technology, New Orleans, (1997), 943-952.

[10] Pask J.A., Importance of starting materials on reactions and haseequilibria in the $\mathrm{Al}_{2} \mathrm{O}_{3}-\mathrm{SiO}_{2}$ system, J. Eur. Ceram. Soc., 16 (1996) 101.

[11] V. Viswabaskaran, F.D. Gnanam, M. Balasubramanian, Mullitisationbehaviour of calcined clay-alumina mixtures, Ceram. Int. 29, (2003) 561-571.

[12] Schneider H., Schrener J., Hildmann B.,Structure and properties of mullite, J. Eur. Ceram. Soc., 28 (2008) 329-344.

[13] Wang J., Piramoon M.R., Ponton C.B., Marcus P.M., A study in short alumina-fiber-reinforced mullite composites, Trans. J. Br. Ceram. Soc. 90 (1991) 105-110.

[14] Mazdiyasni K.S., Brown L.M., Synthesis and mechanical properties of stoichiometric aluminium silicate (mullite), J. Am. Ceram. Soc., 55 (1972) 548-552. 
[15] Aksel C., The role of fine alumina and mullite particles on the thermomechanicalbehaviour of alumina-mullite refractory materials, Mater. Lett., 57 (2002) 708-714.

[16] Sedaghat A., Taheri-Nassaj E., Soraru G.D., Ebadzadeh T., Microstructure development and phase evolution of aluminamullitenanocomposite, Ceram. Int., 40 (2014) 2605-2611.

[17] Claussen N., Le T., Wu S., Claussen N., Le T., Wu S., Low Shrinkage Reaction Bonded Alumina, J. Eur. Ceram. Soc., 5 (1989) 29-35.

[18] Claussen N., Travitzky N.A., Wu S., Tailoring of ReactionBonded $\mathrm{Al}_{2} \mathrm{O}_{3}$ (RBAO) Ceramics, Ceram. Eng. Sci. Proc., 11 (1990) 806-820.

[19] Claussen N., Wu S., Holz D., Reaction-Bonded of Aluminum Oxide (RBAO) composites: processing reaction mechanisms, J. Eur. Ceram. Soc. 14 (1994) 97-109.

[20] Wu S., Claussen N., Fabrication and properties of lowshrinkage reaction-bonded mullite, J. Am. Ceram. Soc., 74 (1991) 2460-63.

[21] Holz D., Pagel S., Bowen C., Wu S.X., Claussen N., Fabrication of low to zero shrinkage reaction-bonded mullite composites, J. Eur. Ceram. Soc., 16 (1996) 255-260.

[22] She J.H., Schneider H., Inoue T., Suzuki M., Sodeoka S., Ueno K., Fabrication of low-shrinkage reaction-bonded alumina-mullite composites, Mater. Chem. Phys., 68 (2001) 105-109.
[23] Ruan G., Zhang Z., Yin M., Xu G., Effect of aluminum powder on the synthesis of cordndum-mullite composites, Ceram - Silikáty, 57 (2013) 133-137.

[24] Aksay I.A., Dabbs D.M., Sarikaya M., Mullite for structural electronic and optical application, J. Am. Ceram. Soc. 74 (1991) 2343-2358.

[25] Todd R.I., Bourke M.A.M., Borsa C.E., Brook R.J., Neutron diffraction measurements of residual stresses in alumina/SiC nano composites, Acta Mater., 45 (1997) 1791-1800.

[26] Luo H.H., Zhang F.C., Roberts S.G., Wear resistance of reaction sintered alumina/mullite composites, Mater. Sci. Eng. A 478 (2008) 270-275.

[27] Kim B.N., Wakayama S., Kawahara M., Characterization of 2dimesional crack propagation behavior simulation and analysis, Int. J. Fracture 75 (1996) 247-259.

[28] Naga S.M., Bondioli F., Wahsh M.M.S., El-Omla M., Utilization of granodiorite in the production of porcelain stoneware tiles, Ceram. Int. 38 (2012) 6267-6272.

[29] Jo W., Kim D. Y., Hwang N. M., effect of interface structure on the microstructural evolution of ceramics,J. Am. Ceram. Soc., 90 (2007) 2293-2295.

[30] Kumazawa T., Kanzaki S., Asaumi J., Kanzaki S., Sinterability of $\mathrm{SiO}_{2}-\mathrm{Al}_{2} \mathrm{O}_{3}$ prepared by spray Pyrolysis effect of chemical composition, J. Ceram. Soc. Jpn., 94 (1986) 485490. 